\title{
The role of adjuvant chemotherapy in nasopharyngeal carcinoma with bulky neck Iymph nodes in the era of IMRT
}

\author{
Tingting $\mathrm{Xu}^{1,2}$, Chunying Shen ${ }^{1,2}$, Xiaomin $\mathrm{Ou}^{1,2}$, Xiayun $\mathrm{He}^{1,2}$, Hongmei Ying ${ }^{1,2}$, \\ Chaosu Hu ${ }^{1,2}$ \\ ${ }^{1}$ Department of Radiation Oncology, Fudan University Shanghai Cancer Center, Shanghai, China \\ ${ }^{2}$ Department of Oncology, Shanghai Medical College, Shanghai, China \\ Correspondence to: Chaosu Hu, e-mail: hucsu62@163.com
}

Keywords: nasopharyngeal carcinoma, locally advanced, N2-3, intensity modulated radiation therapy, adjuvant chemotherapy

Received: September 08, 2015

Accepted: January 29, 2016

Published: March 02, 2016

\begin{abstract}
Nasopharyngeal carcinoma (NPC) patients with N2-3 diseases are prone to develop distant metastasis even treated with standard concurrent chemoradiotherapy (CCRT). Our study is aim to determine the optimal treatment strategy of these patients. Patients with histologically proven NPC were retrospectively analyzed according to the AJCC 2002 stage classification system. A total of 547 patients who had N2-3 diseases were enrolled. They were all treated with Intensity-modulated radiation therapy (IMRT) combined with systemic treatments, including radiotherapy alone (RT alone), neoadjuvant chemotherapy followed by radiotherapy (NACT+RT), CCRT, NACT+CCRT, NACT followed by radiotherapy and adjuvant chemotherapy (NACT+RT+AC), CCRT+AC and NACT+CCRT+AC. A subgroup analysis was also conducted. With a median follow-up time of $\mathbf{5 3 . 8}$ months, adjuvant chemotherapy significantly decreased the risk of distant metastasis (HR $0.413,95 \% \mathrm{CI} 0.194-0.881, p=0.022$ ) as well as significantly increased the OS (HR 0.398, 95\% CI 0.187-0.848, $p=0.017$ ) in patients with N3 disease. The addition of adjuvant chemotherapy seemed to provide benefits to patients with N3 stage NPC and the current study may indicate the need for further randomized investigation.
\end{abstract}

\section{INTRODUCTION}

Platinum-based concurrent chemoradiotherapy represents the gold standard in the treatment of locally advanced nasopharyngeal carcinoma (NPC) $[1,2]$ in the era of $2 \mathrm{D}$ radiotherapy. Intensity-modulated radiation therapy (IMRT) has greatly improved the local control rate to above $90 \%$ [3] but failed to further reduce the distant metastases of patients with bulky lymph nodes (N2-3) [4]. Approximately up to $30-40 \%$ patients with of N3 stage will develop distant failures after radical treatment $[3,5]$. Therefore, it is crucial to choose proper chemotherapeutic modality to maximally reduce distant invasion.

There are limited data of randomized clinical trials with adjuvant chemotherapy to support evidencebased decision-making [6-8]. All studies had failed to demonstrate significant advantage in whole population of locally advanced disease without risk stratification.

On the basis of this background, we retrospectively explored the possible treatment option and hypothesized that patients with bulky lymph nodes would benefit from additional chemotherapy other than the concurrent modality.

\section{RESULTS}

Patient characteristics and treatment modalities

According to the systemic treatment modalities delivered, we classified all 547 patients into non-adjuvant chemotherapy (non-AC) group (341 patients) and adjuvant chemotherapy (AC) group (206 patients). All characteristics except AJCC staging of them were balanced across the two treatment groups in N2-3 population, more stage $\mathrm{IVb}$ (N3) patients were prone to receive $\mathrm{AC}(P=0.005)$. In the subgroup analyses of $407 \mathrm{~N} 2$ and $140 \mathrm{~N} 3$ individuals, with 269 non-AC/138 AC patients and 72 non-AC/68 AC patients included, respectively, all of them had wellbalanced characteristics (Table 1A-1B). Table 2A-2B listed all the treatment modalities administered in those patients. Regimens and cycles of chemotherapy 
Table 1A: Characteristics of 547 N2-3 NPC patients stratified by adjuvant chemotherapy

\begin{tabular}{|c|c|c|c|}
\hline & \multicolumn{3}{|c|}{$\mathrm{N} 2-3(n=547)$} \\
\hline & non-AC group $(\%)(n=341)$ & AC group $(\%)(n=206)$ & $\boldsymbol{P}$ \\
\hline Age & & & 0.097 \\
\hline Median (yrs) & 46 & 48 & \\
\hline Range (yrs) & $7-75$ & $15-70$ & \\
\hline Sex & & & 0.660 \\
\hline Male & $254(74.5)$ & $158(76.7)$ & \\
\hline Female & $87(25.5)$ & $48(23.3)$ & \\
\hline KPS score & & & 0.294 \\
\hline $80-100$ & $338(99.1)$ & $206(100.0)$ & \\
\hline $60-70$ & $3(0.9)$ & $0(0.0)$ & \\
\hline T stage & & & 0.204 \\
\hline $\mathrm{T} 1$ & $79(23.2)$ & $40(19.4)$ & \\
\hline $\mathrm{T} 2 \mathrm{~A} / 2 \mathrm{~B}$ & $134(39.3)$ & $91(44.2)$ & \\
\hline $\mathrm{T} 3$ & $95(27.8)$ & $47(22.8)$ & \\
\hline $\mathrm{T} 4$ & $33(9.7)$ & $28(13.6)$ & \\
\hline AJCC stage & & & $0.005 *$ \\
\hline III & $240(70.4)$ & $118(57.3)$ & \\
\hline IVa & $29(8.5)$ & $20(9.7)$ & \\
\hline $\mathrm{IVb}$ & $72(21.1)$ & $68(33.0)$ & \\
\hline RT dose & & & 0.305 \\
\hline Median (Gy) & 66 & 66 & \\
\hline Range (Gy) & $63.8-77.3$ & $60-74.8$ & \\
\hline
\end{tabular}

* indicated $p<0.05$.

delivered had also been particularized in detail. Among the whole population, $\mathrm{NACT}+\mathrm{CCRT}$ and $\mathrm{NACT}+\mathrm{RT}+\mathrm{AC}$ were the most frequently used regimen in the non-AC group $(43.0 \%)$ and $\mathrm{AC}$ group (33.5\%), respectively, and likewise in the $\mathrm{N} 2(45.0 \%$ and $30.5 \%)$ and $\mathrm{N} 3$ subgroup (37.1\% and $42.2 \%$ ). The cycles of neoadjuvant and concurrent chemotherapy received in different treatment groups were shown in Table 3, and except for the AC, differences of other treatments were not significant.

\section{Treatment failures}

Sites of locoregional relapse and distant metastases for the non-AC and $\mathrm{AC}$ groups were shown in the Table 4A-4B. We compared the failure patterns and discovered no significant differences between non-AC and $\mathrm{AC}$ groups in all N2-3 patients ( $P=0.859$ for relapse and $P=0.345$ for metastasis). Nevertheless, AC was found to reduce the distant metastasis rate significantly in N3 subgroup $(P=0.013)$. Similar relapse rates were found $(9.7 \%$ and $14.7 \%, P=0.610)$ but still more patients progressed in the non-AC group (28/72(38.9\%) vs $23 / 68(33.8 \%), P=0.534)$. Among them, $7 / 17$ (41.2\%) relapsed patients and $24 / 37(64.9 \%)$ metastatic patients died before the last follow-up, respectively.

\section{Survivals}

With a median follow-up time of 53.8 (3.0-79.1) months, AC added no further benefits to all N2-3 NPC patients (Figure 1A-1D). However, in subgroup analyses, the addition of $\mathrm{AC}$ significantly decreased the risk of distant metastasis (HR 0.413, 95\% CI 0.194-0.881, $p=0.022)$ as well as significantly increased the $\mathrm{OS}$ (HR 0.398, 95\% CI 0.187-0.848, $p=0.017$ ) in patients with N3 diseases (Figure 2A-2D). The effect of adjuvant chemotherapy was especially noteworthy for reduction in distant metastatic events, rather than for local or regional recurrences in patients with lymph nodes larger than $6 \mathrm{~cm}$ (N3a) and/or supraclavicular fossa invasion (N3b). 
Table 1B: Characteristics of N2 and N3 subgroup patients stratified by adjuvant chemotherapy

\begin{tabular}{|c|c|c|c|c|c|c|}
\hline & \multicolumn{3}{|c|}{ N2 $(n=407)$} & \multicolumn{3}{|c|}{ N3 $(n=140)$} \\
\hline & $\begin{array}{c}\text { non-AC group } \\
(\%)(n=269)\end{array}$ & $\begin{array}{c}\text { AC group }(\%) \\
\quad(n=138)\end{array}$ & $P$ & $\begin{array}{c}\text { non-AC group } \\
(\%)(n=72)\end{array}$ & $\begin{array}{c}\text { AC group }(\%) \\
(n=68)\end{array}$ & $P$ \\
\hline Age & & & 0.570 & & & 0.080 \\
\hline Median (yrs) & 46 & 47.5 & & 46 & 51 & \\
\hline Range (yrs) & $11-75$ & $15-70$ & & $7-74$ & $16-68$ & \\
\hline Sex & & & 0.386 & & & 0.106 \\
\hline Male & $204(75.8)$ & $102(73.9)$ & & $50(69.4)$ & $56(82.4)$ & \\
\hline Female & $65(24.2)$ & $36(26.1)$ & & $22(30.6)$ & $12(17.6)$ & \\
\hline KPS score & & & 0.554 & & & 1.000 \\
\hline $80-100$ & $266(98.9)$ & $138(100.0)$ & & $72(100.0)$ & $68(100.0)$ & \\
\hline $60-70$ & $3(1.1)$ & $0(0.0)$ & & $0(0.0)$ & $0(0.0)$ & \\
\hline T stage & & & 0.684 & & & 0.252 \\
\hline $\mathrm{T} 1$ & 57 (21.2) & 27 (19.6) & & $22(30.5)$ & $13(19.1)$ & \\
\hline $\mathrm{T} 2 \mathrm{~A} / 2 \mathrm{~B}$ & $105(39.0)$ & $58(42.0)$ & & $29(40.3)$ & $33(48.5)$ & \\
\hline $\mathrm{T} 3$ & $78(29.0)$ & 33 (23.9) & & 17 (23.6) & $14(20.6)$ & \\
\hline $\mathrm{T} 4$ & $29(10.8)$ & $20(14.5)$ & & $4(5.6)$ & $8(11.8)$ & \\
\hline AJCC stage & & & 0.334 & & & 1.000 \\
\hline III & $240(89.2)$ & $118(85.5)$ & & $0(0.0)$ & $0(0.0)$ & \\
\hline IVa & $29(10.8)$ & $20(14.5)$ & & $0(0.0)$ & $0(0.0)$ & \\
\hline $\mathrm{IVb}$ & $0(0.0)$ & $0(0.0)$ & & $72(100.0)$ & $68(100.0)$ & \\
\hline RT dose & & & 0.848 & & & 0.280 \\
\hline Median (Gy) & 66 & 66 & & 66 & 66 & \\
\hline Range (Gy) & $63.8-74.4$ & $60-74.8$ & & $66-77.3$ & $62.8-70.4$ & \\
\hline
\end{tabular}

In a further exploratory analysis, different chemotherapy regimens also engendered different consequences (Table 5). TPF and GP were demonstrated to have a trend to be superior to PF in improving OS, but the difference not significant $(89.3 \%$ and $86.8 \%$ vs $71.6 \%$, $P=0.157)$. The chemotherapy cycles delivered were not associated with the outcomes, either.

\section{DISCUSSION}

The clinical advantages of IMRT in the treatment of NPC with respect to both disease control and adverseeffect profiles have been repeated demonstrated [9-14]. It was not difficult to understand that the benefit of locoregional control derived from concurrent chemotherapy would be weakened by the modern radiotherapy technique (IMRT). Distant metastasis became the main treatment failure pattern in locally advanced NPC especially with advanced $\mathrm{N}$ stage.
It is important to realize that patients with bulky neck lymph nodes (especially N3) are a heterogeneous group, and thus the strategies for treatment should differ depending on the lymph nodal status of the individual patient. Several studies had demonstrated that N3 patients would have more chances to develop metastases hence achieved poorer overall survival rates. Cheng et al. [15] found the 3-year DMFS rate were $92 \%, 84 \%$ and $56 \%$ $(P=0.003)$ in $\mathrm{N} 0-1, \mathrm{~N} 2$ and $\mathrm{N} 3$ subgroup, respectively. $\mathrm{T} 4$ and N3 were discovered to be two independent prognostic factors to influent distant metastases in further Cox regression analysis. This is consistent with Liu's series [16] in which the 3-year OS rate of N1-2 was $85 \%$ and sharply down to $58 \%$ in N3 patients $(P=0.046)$.

Despite being the NCCN recommendation for locally advanced NPC, CCRT may not always be the only choice. In Lin's study [17], patients were divided into different metastatic risk subgroups by nodal status and tumor stage. CCRT was proved to be superior to RT alone 
Table 2A: Treatment regimens of 547 N2-3 NPC patients stratified by adjuvant chemotherapy

\begin{tabular}{|l|c|c|}
\hline \multicolumn{2}{|c|}{ Non-AC group (\%) $(\boldsymbol{n}=\mathbf{3 4 1})$} & AC group (\%) (n= 206) \\
\hline Treatment modality & & 0 \\
\hline RT alone & $14(2.6)$ & 0 \\
\hline NACT+RT & $65(11.9)$ & 0 \\
\hline CCRT & $27(4.9)$ & 0 \\
\hline NACT +CCRT & $235(43.0)$ & $3(0.5)$ \\
\hline CCRT+AC & 0 & $183(33.5)$ \\
\hline NACT+RT+AC & 0 & $20(3.6)$ \\
\hline NACT+CCRT+AC & 0 & $62(30.1)$ \\
\hline CT Regimen & & $86(41.7)$ \\
\hline PF & N/A & $58(28.2)$ \\
\hline TPF & N/A & $82(39.8)$ \\
\hline GP & N/A & $63(30.6)$ \\
\hline AC cycles & N/A & $61(29.6)$ \\
\hline 1 cycle & N/A & N/A \\
\hline 2 cycles & N & \\
\hline 3 cycles & & \\
\hline
\end{tabular}

Abbreviations: $\mathrm{RT}=$ radiotherapy; NACT $=$ neoadjuvant chemotherapy; CCRT $=$ concurrent chemoradiotherapy; $\mathrm{AC}=$ adjuvant chemotherapy; $\mathrm{CT}=$ chemotherapy.

Table 2B: Treatment regimens of $\mathrm{N} 2$ and $\mathrm{N} 3$ subgroup patients stratified by adjuvant chemotherapy

\begin{tabular}{|c|c|c|c|c|}
\hline & \multicolumn{2}{|c|}{ N2 $(n=407)$} & \multicolumn{2}{|c|}{$\mathrm{N} 3(n=140)$} \\
\hline & $\begin{array}{l}\text { non-AC group (\%) } \\
(n=269)\end{array}$ & $\begin{array}{c}\text { AC group (\%) } \\
(n=138)\end{array}$ & $\begin{array}{c}\text { non-AC group (\%) } \\
(n=72)\end{array}$ & $\begin{array}{c}\text { AC group (\%) } \\
(n=68)\end{array}$ \\
\hline \multicolumn{5}{|l|}{ Treatment modality } \\
\hline RT alone & $13(3.2)$ & 0 & $1(0.7)$ & 0 \\
\hline $\mathrm{NACT}+\mathrm{RT}$ & $50(12.3)$ & 0 & $15(10.7)$ & 0 \\
\hline CCRT & $23(5.7)$ & 0 & $4(2.9)$ & 0 \\
\hline NACT +CCRT & $183(45.0)$ & 0 & $52(37.1)$ & 0 \\
\hline $\mathrm{CCRT}+\mathrm{AC}$ & 0 & $2(0.5)$ & 0 & $1(0.7)$ \\
\hline $\mathrm{NACT}+\mathrm{RT}+\mathrm{AC}$ & 0 & $124(30.5)$ & 0 & $59(42.2)$ \\
\hline $\mathrm{NACT}+\mathrm{CCRT}+\mathrm{AC}$ & 0 & $12(2.9)$ & 0 & $8(5.7)$ \\
\hline \multicolumn{5}{|l|}{ CT Regimen } \\
\hline $\mathrm{PF}$ & N/A & $57(41.3)$ & $\mathrm{N} / \mathrm{A}$ & $29(42.7)$ \\
\hline TPF & N/A & $49(35.5)$ & $\mathrm{N} / \mathrm{A}$ & $13(19.1)$ \\
\hline GP & N/A & $32(23.2)$ & N/A & $26(38.2)$ \\
\hline \multicolumn{5}{|l|}{ AC cycles } \\
\hline 1 cycle & N/A & $54(39.1)$ & N/A & $28(41.2)$ \\
\hline 2 cycles & N/A & $37(26.8)$ & N/A & $26(38.2)$ \\
\hline 3 cycles & N/A & $47(34.1)$ & N/A & $14(20.6)$ \\
\hline
\end{tabular}

Abbreviations: $\mathrm{RT}=$ radiotherapy; $\mathrm{NACT}=$ neoadjuvant chemotherapy; $\mathrm{CCRT}=$ concurrent chemoradiotherapy; $\mathrm{AC}=$ adjuvant chemotherapy; $\mathrm{CT}=$ chemotherapy. 
Table 3: The cycles of NACT and CCT received in different treatment groups

Non-AC group (\%)

\begin{tabular}{|c|c|c|c|c|}
\hline & & $\mathrm{NACT}+\mathrm{RT}$ & $\mathrm{NACT}+\mathrm{RT}+\mathrm{AC}$ & $P$ value \\
\hline \multirow[t]{4}{*}{ NACT cycles } & 1 & $4(6.2)$ & $8(4.4)$ & 0.742 \\
\hline & 2 & $42(64.6)$ & $114(62.3)$ & \\
\hline & 3 & $19(29.2)$ & $61(33.3)$ & \\
\hline & & CCRT & $\mathrm{CCRT}+\mathrm{AC}$ & $P$ value \\
\hline \multirow[t]{3}{*}{ CCT cycles } & $<5$ & $16(59.3)$ & $1(33.3)$ & 0.565 \\
\hline & $\geq 5$ & $11(40.7)$ & $2(66.7)$ & \\
\hline & & $\mathrm{NACT}+\mathrm{CCRT}$ & $\mathrm{NACT}+\mathrm{CCRT}+\mathrm{AC}$ & $P$ value \\
\hline \multirow[t]{3}{*}{ NACT cycles } & 1 & $4(1.7)$ & $0(0.0)$ & 0.384 \\
\hline & 2 & $177(75.3)$ & $13(65.0)$ & \\
\hline & 3 & $54(23.0)$ & $7(35.0)$ & \\
\hline \multirow[t]{2}{*}{ CCT cycles } & $<5$ & $132(56.2)$ & $9(45.0)$ & 0.358 \\
\hline & $\geq 5$ & $103(43.8)$ & $11(55.0)$ & \\
\hline
\end{tabular}

Abbreviations: $\mathrm{NACT}=$ neoadjuvant chemotherapy; $\mathrm{CCRT}=$ concurrent chemoradiotherapy; $\mathrm{CCT}=$ concurrent chemotherapy; $\mathrm{AC}=$ adjuvant chemotherapy.

Table 4A: Treatment failure patterns of 547 N2-3 NPC patients stratified by adjuvant chemotherapy N2-3 $(n=547)$

\begin{tabular}{|c|c|c|c|}
\hline \multicolumn{2}{|c|}{$\begin{array}{c}\text { non-AC group (\%) } \\
(n=341) \\
(n=206)\end{array}$} & 0.859 \\
\hline Relapses & & $5(2.4)$ & \\
\hline Nasopharynx & $12(3.5)$ & $4(2.0)$ & \\
\hline Base of skull & $6(1.8)$ & $8(3.9)$ & \\
\hline Neck & $18(5.3)$ & $5(2.4)$ & \\
\hline Naso+neck & $10(2.9)$ & $22(10.7)$ & 0.345 \\
\hline Total & $46(13.5)$ & $184(89.3)$ & \\
\hline No relapse & $295(86.5)$ & & \\
\hline Metastases & & $15(1.5)$ & \\
\hline Liver & $14(4.1)$ & $13(6.3)$ & \\
\hline Bone & $29(8.5)$ & $2(0.9)$ & \\
\hline Lung & $13(3.8)$ & $6(2.9)$ & \\
\hline Other & $5(1.5)$ & $39(18.9)$ & $167(81.1)$ \\
\hline Multiple & $12(3.5)$ & & \\
\hline Total & $73(21.4)$ & & \\
\hline No metastasis & $268(78.6)$ & & \\
\hline
\end{tabular}


Table 4B: Treatment failure patterns of $\mathrm{N} 2$ and $\mathrm{N} 3$ subgroup patients stratified by adjuvant chemotherapy

\begin{tabular}{|c|c|c|c|c|c|c|}
\hline & \multicolumn{3}{|c|}{$\mathrm{N} 2(n=407)$} & \multicolumn{3}{|c|}{$\mathrm{N} 3(n=140)$} \\
\hline & $\begin{array}{c}\text { non-AC group } \\
(\%)(n=269)\end{array}$ & $\begin{array}{c}\text { AC group }(\%) \\
\quad(n=138)\end{array}$ & $P$ & $\begin{array}{c}\text { non-AC group } \\
(\%)(n=72)\end{array}$ & $\begin{array}{c}\text { AC group (\%) } \\
(n=68)\end{array}$ & $P$ \\
\hline Relapses & & & 0.114 & & & 0.610 \\
\hline Nasopharynx & $11(4.1)$ & $3(2.2)$ & & $1(1.4)$ & $2(2.9)$ & \\
\hline Base of skull & $5(1.8)$ & $3(2.2)$ & & $1(1.4)$ & $1(1.5)$ & \\
\hline Neck & $14(5.2)$ & $5(3.6)$ & & $4(5.5)$ & $3(4.4)$ & \\
\hline Naso+neck & $9(3.3)$ & $1(0.7)$ & & $1(1.4)$ & $4(5.9)$ & \\
\hline Total & $39(14.5)$ & $12(8.7)$ & & $7(9.7)$ & $10(14.7)$ & \\
\hline No relapse & $230(85.5)$ & $126(91.3)$ & & $65(90.3)$ & $58(85.3)$ & \\
\hline Metastases & & & 0.893 & & & $0.013^{*}$ \\
\hline Liver & $11(4.1)$ & $3(2.2)$ & & $3(4.1)$ & $0(0.0)$ & \\
\hline Bone & $14(5.2)$ & $9(6.5)$ & & $15(20.8)$ & $6(8.8)$ & \\
\hline Lung & $10(3.7)$ & $11(8.0)$ & & $3(4.2)$ & $2(2.9)$ & \\
\hline Other & $3(1.1)$ & $2(1.4)$ & & $2(2.8)$ & $0(0.0)$ & \\
\hline Multiple & $11(4.1)$ & $1(0.7)$ & & $1(1.4)$ & $5(7.4)$ & \\
\hline Total & $49(18.2)$ & $26(18.8)$ & & $24(33.3)$ & $13(19.1)$ & \\
\hline No metastasis & $220(81.8)$ & $112(81.2)$ & & $48(66.7)$ & $55(80.9)$ & \\
\hline
\end{tabular}

* indicated $p<0.05$.

for low-risk patients $(83.2 \%$ vs $59.7 \%$ for OS at 5 -year $P=0.004)$ but inadequate for high-risk ones $(55.8 \%$ vs $46.3 \%$ for OS at 5 -year $P=0.176$ ). It is reasonable to presume that an alternative modality should be further explored for advanced $\mathrm{N}$ patients.

The question remains unclear whether increasing chemotherapy intensity can improve the outcome of those patients. Several randomized studies [6-8] have attempted to identify the effectiveness of adjuvant chemotherapy in locally advanced diseases (stage III-IVb) and failed to get the expected outcomes. It's a pity that none of them had focused on this specific subgroup. The deficiency of the most published works was that they treated patients without stratification.

We were first to report the achievements by different lymph nodal status. In this retrospective study, the addition of adjuvant chemotherapy seemed to provide delightful benefit to patients with N3 stage NPC. The overall survival was largely improved in terms of the reduced distant metastasis. In the analyses of failure patterns, similar relapse rates $(9.7 \%$ vs $14.7 \%, P=0.610)$ and more metastasis rates $(33.3 \%$ vs $19.1 \%, P=0.013)$ were shown in the non-AC group (Figure 3A-3B). Among these disease progressions, more metastatic patients (64.9\% vs $41.2 \%)$ died before the last follow-up. As a result, the differences were still significant in terms of OS. It could be explained by that patients who developed metastases had lost the limitation of diseases and would have more complications thus resulted in shorter survival times. We postulated that metastasis rather than relapse was the determined factor of overall survival. The key of improving outcomes of NPC patients with bulky lymph nodes should be finding a way to reduce the distant metastasis. Systemic chemotherapy is an effective treatment for diminishing micro-metastases that cannot be detected by regular imagining with increased side effects. In the current cohort, $\mathrm{AC}$ had showed promisingly survival benefits for N3 patients, indicating delivering chemotherapy after the radical radiotherapy might further decrease the risk of distant metastases.

It had been discovered as well that although TPF and GP were demonstrated to have a trend to be superior to PF in improving OS, the $P$ value was still not significant due to the relatively small sample size. As already confirmed by randomized trails $[18,19]$ and meta-analysis $[20]$ in head and neck squamous cell carcinoma (HNSCC), the TPF regimen is accepted to be a better choice than PF in HNSCC patients who received NACT. Nevertheless, the conclusion is still pending in NPC, randomized investigation are warranted. Moreover, It's not easy to balance the efficacies and toxicities when treating patients, and we must realize that it's also an important affair to recognize predictive factors to select patients who may really have greater benefit from adjuvant therapy. 
A

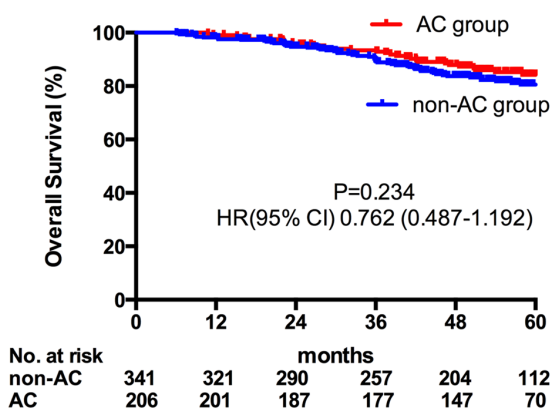

C

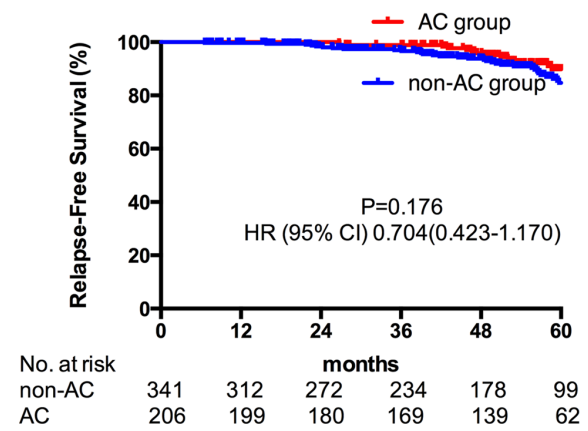

B

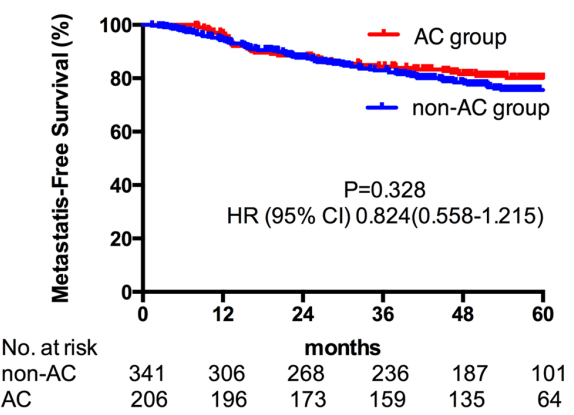

D

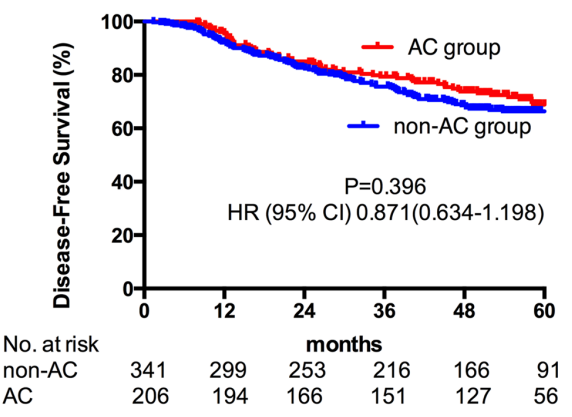

Figure 1: Kaplan-Meier estimate of OS (A), DMFS (B), LRFS (C) and DFS (D) in all N2-3 patients stratified by adjuvant chemotherapy.

A

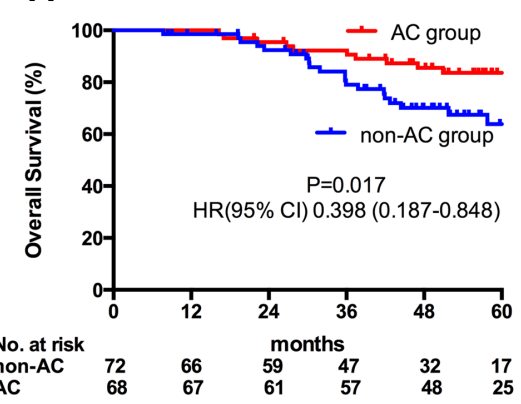

C

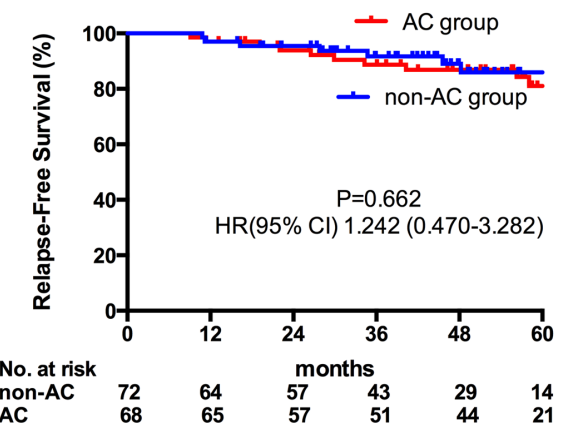

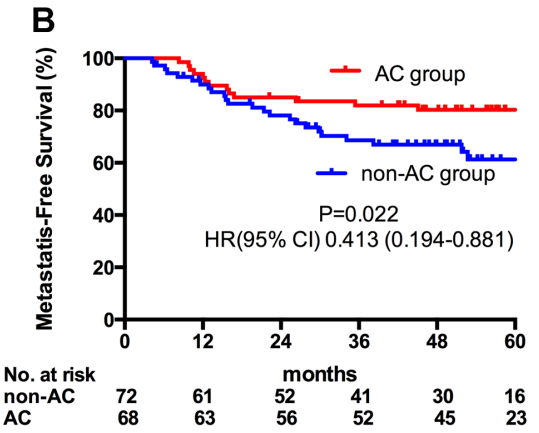

D

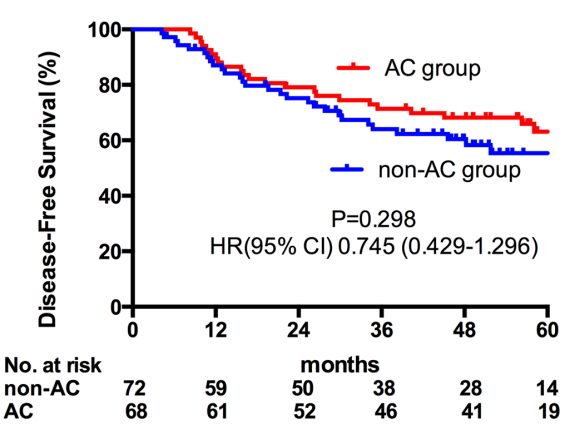

Figure 2: Kaplan-meier estimate of OS (A), DMFS (B), LRFS (C) and DFS (D) in N3 patients stratified by adjuvant chemotherapy. 
Table 5: Relationships between the regimens/cycles of adjuvant chemotherapy and survival outcomes in $\mathbf{N} 3$ population

\begin{tabular}{|c|c|c|c|c|c|c|}
\hline & Regimens & Survival rates & $P$ & Cycles & Survival rates & $P$ \\
\hline \multirow[t]{3}{*}{$4 y$ OS } & TPF & $89.3 \%$ & 0.157 & 1 & $85.2 \%$ & 0.580 \\
\hline & $\mathrm{PF}$ & $71.6 \%$ & & 2 & $86.9 \%$ & \\
\hline & GP & $86.8 \%$ & & 3 & $81.8 \%$ & \\
\hline \multirow[t]{3}{*}{ 4y DMFS } & $\mathrm{TPF}$ & $79.3 \%$ & 0.592 & 1 & $82.1 \%$ & 0.892 \\
\hline & $\mathrm{PF}$ & $91.7 \%$ & & 2 & $76.5 \%$ & \\
\hline & GP & $76.5 \%$ & & 3 & $84.6 \%$ & \\
\hline \multirow[t]{3}{*}{ 4y LRFS } & $\mathrm{TPF}$ & $92.7 \%$ & 0.162 & 1 & $88.2 \%$ & 0.245 \\
\hline & $\mathrm{PF}$ & $71.4 \%$ & & 2 & $87.8 \%$ & \\
\hline & GP & $86.5 \%$ & & 3 & $80.8 \%$ & \\
\hline \multirow[t]{3}{*}{$4 y$ DFS } & $\mathrm{TPF}$ & $72.4 \%$ & 0.832 & 1 & $71.4 \%$ & 0.594 \\
\hline & $\mathrm{PF}$ & $64.3 \%$ & & 2 & $65.2 \%$ & \\
\hline & GP & $64.6 \%$ & & 3 & $65.9 \%$ & \\
\hline
\end{tabular}

Abbreviations: OS = Overall Survival; DMFS = Distant Metastasis-Free Survival; LRFS = Locoregional Relapse-Free Survival; DFS = Disease-Free Survival.

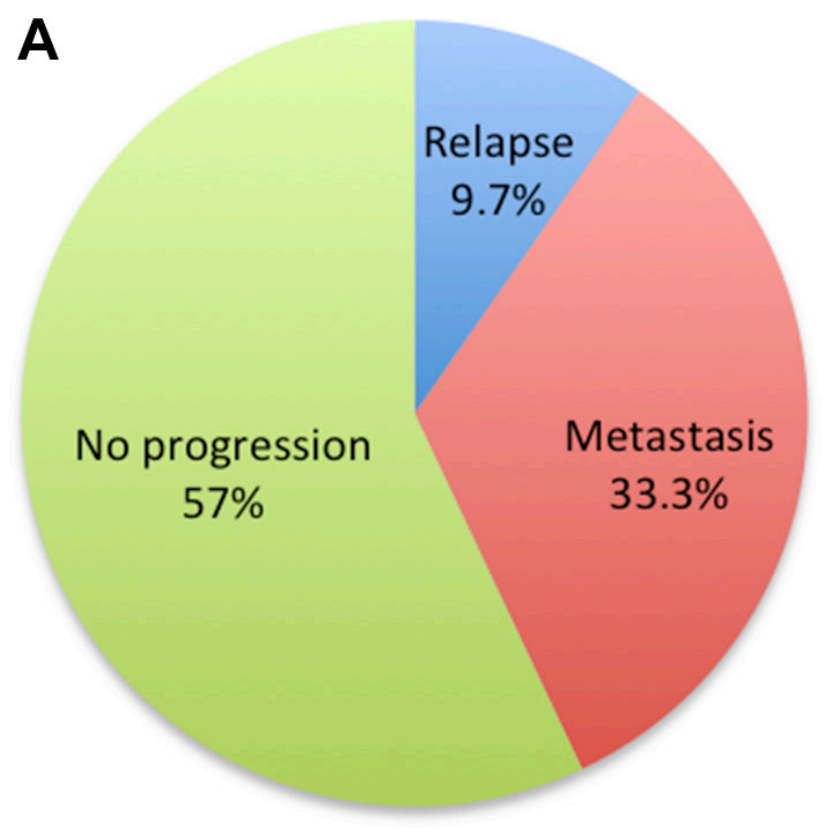

B

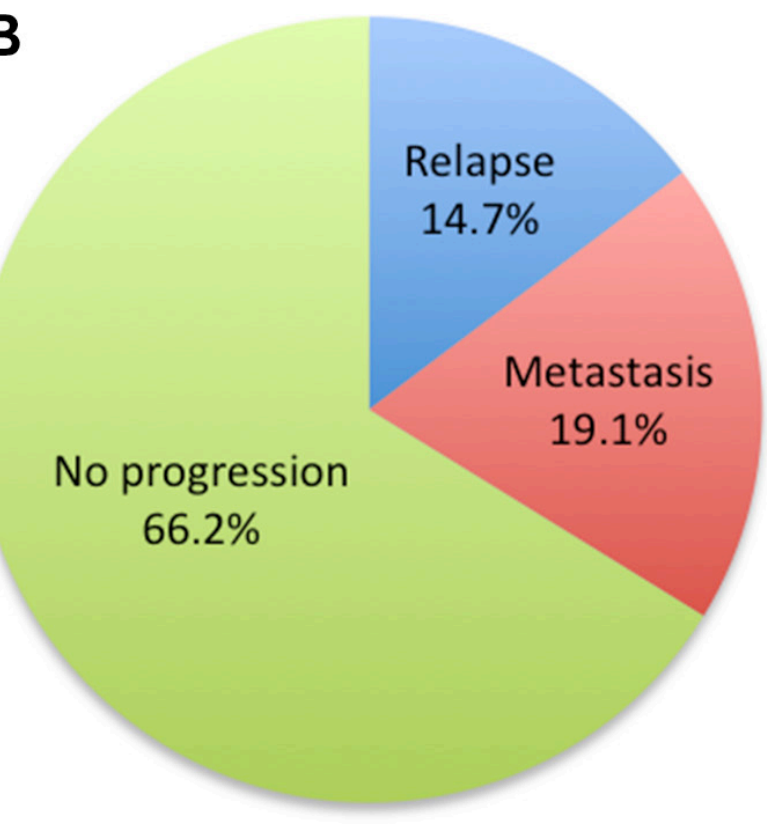

Figure 3: Pie charts of treatment failure patterns of non-AC (A) and AC (B) groups. 


\section{MATERIALS AND METHODS}

\section{Patient selection}

Between November 2008 and November 2011, a total of 547 any T (T1-4), N2-3, without metastatic disease (M0), NPC patients (according to the AJCC 2002 stage classification system) treated with IMRT-based systemic therapy at Fudan University Shanghai Cancer Center were retrospectively enrolled. Pretreatment evaluation consisted of complete history and physical examination, complete blood cell count, biochemical profile, contrasted-MRI of the nasopharynx and neck, chest $\mathrm{CT}$, ultrasound of the abdomen, bone scan and/or $\mathrm{PET} / \mathrm{CT}$.

\section{Treatment}

All 547 patients underwent the same radical radiotherapy (IMRT) and different systemic treatments including radiotherapy alone (RT alone), neoadjuvant chemotherapy followed by radiotherapy (NACT+RT), concurrent chemoradiotherapy (CCRT), neoadjuvant chemotherapy followed by concurrent chemoradiotherapy (NACT $+\mathrm{CCRT}), \quad$ concurrent chemoradiotherapy followed by adjuvant chemotherapy (CCRT $+\mathrm{AC})$, neoadjuvant chemotherapy followed by radiotherapy and adjuvant chemotherapy (NACT $+\mathrm{RT}+\mathrm{AC}$ ), neoadjuvant chemotherapy followed by concurrent chemoradiotherapy and adjuvant chemotherapy (NACT $+\mathrm{CCRT}+\mathrm{AC}$ ). Treatment strategy of each patient was made by his/her radiation oncologist.

The IMRT treatment plans were designed and optimized using an inverse planning system (Pinnacle 3, Philips). 6-MV photons were used to treat primary tumors and neck drainage areas. The gross tumor volume (GTV) was delineated based on the findings of MRI. The clinical target volume (CTV) was delineated with adequate margins surrounding the GTV considering the anatomic boundary of the possibly involved subsites. The prescription doses were $66 \mathrm{~Gy} / 30 \mathrm{Fx}$ and $70.4 \mathrm{~Gy} / 32 \mathrm{Fx}$ to T1-2 and T3-4 primary diseases, respectively. All metastatic lymph nodes detected on MRI were treated with a prescription dose of $66 \mathrm{~Gy}$.

In patients received CCRT, cisplatin was delivered weekly at a dose of $40 \mathrm{mg} / \mathrm{m}^{2}$ concurrently with radiotherapy.

In patients received neoadjuvant/adjuvant chemotherapy, the choice of chemotherapy regimen was left to the discretion of the treating medical oncologist. Generally, one of three cisplatin-based neoadjuvant/ adjuvant regimens for $1-3$ cycles were delivered: $\mathrm{PF}$ (DDP $75 \mathrm{mg} / \mathrm{m}^{2} \mathrm{~d} 1+5-\mathrm{FU} 500 \mathrm{mg} / \mathrm{m}^{2} / \mathrm{d}$ with $120-\mathrm{h}$ infusion), TPF (docetaxel $75 \mathrm{mg} / \mathrm{m}^{2} \mathrm{~d} 1+$ DDP $75 \mathrm{mg} / \mathrm{m}^{2}$ d1-3+5-FU $500 \mathrm{mg} / \mathrm{m}^{2} / \mathrm{d}$ with 120 -h infusion) or GP (gemcitabine $1.0 \mathrm{~g} / \mathrm{m}^{2} \mathrm{~d} 1$, d8+DDP $75 \mathrm{mg} / \mathrm{m}^{2} \mathrm{~d} 1$ ). The regimens were repeated every 21 days for neoadjuvant phase and every 4 weeks for adjuvant phase. A total of 2-3 cycles of NACT, 6-7 cycles of concurrent chemotherapy and 2 cycles of AC were assigned in each modality. Patients who had residual disease after finished the planned treatment would receive the third cycle of AC if tolerable.

Follow-up data were to be collected every 3 months through the first two years, every 6 months during years 3-5 and every 12 months in years $6-10$ for all patients.

\section{Endpoints and statistical analysis}

The Kaplan-Meier model was used to estimate the survival. Differences in survivals between subgroups were compared with log-rank test. The primary end point of the study was the overall survival (OS). In the analysis of OS, a patient was considered to have death if he dead as a result of any cause. Other outcomes of interest included distant metastasis-free survival (DMFS), locoregional relapse-free survival (LRFS) and disease-free survival (DFS). DFS was defined as the time from diagnosis confirmed to relapsed/metastasized. LRFS and DMFS were defined as the duration from the date of diagnosis confirmed to locoregional relapse and distant metastasis, respectively. The $\chi^{2}$ test was used to detect statistical differences in proportions. All statistical analyses were performed using SPSS software (version 20.0). A twosided $\boldsymbol{p}$ value $<0.05$ was considered to be significant. The survival curves were completed using GraphPad Prism 6.0 software.

\section{ACKNOWLEDGMENTS}

We thank Ms. Yanping Xu, Ms. Jing Yuan, Ms. Xin Zhou, Ms. Qi Shi, Ms. Xing Xing and Ms. Wen Jiang for their kind help of data collection and patient follow-up.

\section{FUNDING}

None declared.

\section{CONFLICTS OF INTEREST}

There is no conflicts or interest.

\section{REFERENCES}

1. Al-Sarraf M, LeBlanc M, Giri PG, Fu KK, Cooper J, Vuong T, Forastiere AA, Adams G, Sakr WA, Schuller DE, Ensley JF. Chemoradiotherapy versus radiotherapy in patients with advanced nasopharyngeal cancer: phase III randomized Intergroup study 0099. J Clin Oncol. 1998; 16:1310-1317. 
2. Blanchard P, Lee A, Marguet S, Leclercq J, Ng WT, Ma J, Chan AT, Huang PY, Benhamou E, Zhu G, Chua DT, Chen Y, Mai HQ, et al; MAC-NPC Collaborative Group. Chemotherapy and radiotherapy in nasopharyngeal carcinoma: an update of the MAC-NPC meta-analysis. Lancet Oncol. 2015; 16:645-655.

3. Lai SZ, Li WF, Chen L, Luo W, Chen YY, Liu LZ, Sun Y, Lin AH, Liu MZ, Ma J. How Does Intensity-Modulated Radiotherapy Versus Conventional Two-Dimensional Radiotherapy Influence the Treatment Results in Nasopharyngeal Carcinoma Patients? Int J Radiat Oncol Biol Phys. 2011; 80:661-668.

4. Li AC, Xiao WW, Shen GZ, Wang L, Xu AA, Cao YQ, Huang SM, Lin CG, Han F, Deng XW, Zhao C. Distant metastasis risk and patterns of nasopharyngeal carcinoma in the era of IMRT: long-term results and benefits of chemotherapy. Oncotarget. 2015 May 28. [Epub ahead of print]. doi: 10.18632/oncotarget.4312.

5. Sun X, Su S, Chen C, Han F, Zhao C, Xiao W, Deng X, Huang S, Lin C, Lu T. Long-term outcomes of intensity-modulated radiotherapy for 868 Patients with nasopharyngeal carcinoma: an analysis of survival and treatment toxicities. Radiother Oncol, 2014; 110:398-403.

6. Rossi A, Molinari R, Boracchi P, Del Vecchio M, Marubini E, Nava M, Morandi L, Zucali R, Pilotti S, Grandi C. Adjuvant chemotherapy with vincristine, cyclophosphamide, and doxorubicin after radiotherapy in local-regional nasopharyngeal cancer: results of a 4-year multicenter randomized study. J Clin Oncol. 1988; 6: 1401-1410.

7. Chi KH, Chang YC, Guo WY, Leung MJ, Shiau CY, Chen SY, Wang LW, Lai YL, Hsu MM, Lian SL, Chang CH, Liu TW, Chin YH, et al. A phase III study of adjuvant chemotherapy in advanced nasopharyngeal carcinoma patients. Int J Radiat Oncol Biol Phys. 2002; 52:1238-1244.

8. Chen L, Hu CS, Chen XZ, Hu GQ, Cheng ZB, Sun Y, Li WX, Chen YY, Xie FY, Liang SB, Chen Y, Xu TT, Li B, et al. Concurrent chemoradiotherapy plus adjuvant chemotherapy versus concurrent chemoradiotherapy alone in patients with locoregionally advanced nasopharyngeal carcinoma: a phase 3 multicentre randomised controlled trial. Lancet Oncol. 2012; 13:163-171.

9. Lee N, Xia P, Quivey JM, Sultanem K, Poon I, Akazawa C, Akazawa P, Weinberg V, Fu KK. Intensity-modulated radiotherapy in the treatment of nasopharyngeal carcinoma: an update of the UCSF experience. Int J Radiat Oncol Biol Phys. 2002; 53:12-22.

10. Kwong DL, Pow EH, Sham JS, McMillan AS, Leung LH, Leung WK, Chua DT, Cheng AC, Wu PM, Au GK. Intensity-modulated radiotherapy for early-stage nasopharyngeal carcinoma: a prospective study on disease control and preservation of salivary function. Cancer. 2004; 101:1584-1593.

11. Wolden SL, Chen WC, Pfister DG, et al. Intensitymodulated radiation therapy (IMRT) for nasopharynx cancer: update of the Memorial Sloan-Kettering experience. Int J Radiat Oncol Biol Phys. 2006; 64:57-62.

12. Wolden SL, Chen WC, Pfister DG, Kraus DH, Berry SL, Zelefsky MJ. Intensity-modulated radiation therapy with or without chemotherapy for nasopharyngeal carcinoma: radiation therapy oncology group phase II trial 0225 . J Clin Oncol. 2009; 27:3684-3690.

13. Tham IW, Hee SW, Yeo RM, Salleh PB, Lee J, Tan TW, Fong KW, Chua ET, Wee JT. Treatment of nasopharyngeal carcinoma using intensity-modulated radiotherapy-The National Cancer Centre Singapore experience. Int J Radiat Oncol Biol Phys. 2009; 75:1481-1488.

14. Ng WT, Lee MC, Hung WM, Choi CW, Lee KC, Chan OS, Lee AW. Clinical outcomes and patterns of failure after intensity-modulated radiotherapy for nasopharyngeal carcinoma. Int J Radiat Oncol Biol Phys. 2011; 79:420-428.

15. Cheng SH, Yen KL, Jian JJ, Tsai SY, Chu NM, Leu SY, Chan KY, Tan TD, Cheng JC, Hsieh CY, Huang AT. Examining prognostic factors and patterns of failure in nasopharyngeal carcinoma following concomitant radiotherapy and chemotherapy: impact on future clinical trials. Int J Radiat Oncol Biol Phys. 2001; 50:717-726.

16. Liu MT, Hsieh CY, Chang TH, Lin JP, Huang CC, Wang AY. Prognostic factors affecting the outcome of nasopharyngeal carcinoma. Jpn J Clin Oncol. 2003; 33:501-508.

17. Lin JC, Liang WM, Jan JS, Jiang RS, Lin AC. Another way to estimate out- come of advanced nasopharyngeal carcinoma-is concurrent chemoradiotherapy adequate? Int J Radiat Oncol Biol Phys. 2004; 60:156-164.

18. Vermorken JB, Remenar E, van Herpen C, Gorlia T, Mesia R, Degardin M, Stewart JS, Jelic S, Betka J, Preiss JH, van den Weyngaert D, Awada A, Cupissol D, et al; EORTC 24971/TAX 323 Study Group. Cisplatin, fluorouracil, and docetaxel in unresecTable head and neck cancer. N Engl J Med. 2007; 357:1695-1704.

19. Lorch JH, Goloubeva O, Haddad RI, Cullen K, Sarlis N, Tishler R, Tan M, Fasciano J, Sammartino DE, Posner MR; TAX 324 Study Group. Induction chemotherapy with cisplatin and fluorouracil alone or in combination with docetaxel in locally advanced squamous-cell cancer of the head and neck: long-term results of the TAX 324 randomised phase 3 trial. Lancet Oncol. 2011; 12: 153-159.

20. Blanchard P, Bourhis J, Lacas B, Posner MR, Vermorken JB, Hernandez JJ, Bourredjem A, Calais G, Paccagnella A, Hitt R, Pignon JP; Meta-Analysis of Chemotherapy in Head and Neck Cancer, Induction Project, Collaborative Group. Taxane-cisplatin-fluorouracil as induction chemotherapy in locally advanced head and neck cancers: an individual patient data meta-analysis of the meta-analysis of chemotherapy in head and neck cancer group. J Clin Oncol. 2013; 31:2854-2860. 